American Journal of Environmental Sciences 1 (4): 264-269, 2005

ISSN 1553-345X

(C) 2005 Science Publications

\title{
Supercritical Fluid Extraction of Palm Carotenoids
}

\author{
${ }^{1,2}$ Puah Chiew Wei, ${ }^{1}$ Choo Yuen May, ${ }^{1}$ Ma Ah Ngan and ${ }^{2}$ Chuah Cheng Hock \\ ${ }^{1}$ Malaysian Palm Oil Board, Bandar Baru Bangi, 43000 Kajang, Selangor, Malaysia \\ ${ }^{2}$ Department of Chemistry, Faculty of Science, University of Malaya \\ Lembah Pantai, 50603 Kuala Lumpur, Malaysia
}

\begin{abstract}
The extraction of carotenoids from crude palm oil was carried out in a dynamic (flowthrough) supercritical fluid extraction system. The carotenoids obtained were quantified using off-line UV-visible spectrophotometry. The effects of operating pressure and temperature, flow rate of the supercritical carbon dioxide (SC- $\mathrm{CO}_{2}$ ), sample size of feed used on the solubility of palm carotenoids were investigated. The results showed that the extraction of carotenoids was governed by its solubility in the $\mathrm{SC}-\mathrm{CO}_{2}$ and can be enhanced by increasing pressure at a constant temperature or decreasing temperature at a constant pressure. Increasing the flow rate and decreasing the sample size can reduce the extraction time but do not enhance the solubility. Palm carotenoids have very low solubility in SC$\mathrm{CO}_{2}$ in the range of $1.31 \times 10^{-4} \mathrm{~g} \mathrm{~kg}^{-1}$ to $1.58 \times 10^{-3} \mathrm{~g} \mathrm{~kg}^{-1}$ for the conditions investigated in this study. The experimental data obtained were compared with those published by other workers and correlated by a density-based equation as proposed by Chrastil.
\end{abstract}

Keywords: Carbon dioxide, palm oil, pressure, solubility, temperature

\section{INTRODUCTION}

Carotenoids have been proven to be beneficial to human health apart from having pro-vitamin A which prevents xeropthlamia, a night blindness disease. Carotenoids also play an important role as anti-oxidant by scavenging free radicals ${ }^{[1]}$ and as singlet oxygen quencher ${ }^{[2]}$. Carotenoids are also found to be capable of inhibiting growth of certain cancer cells such as the colon cancer ${ }^{[3]}$.

The commercially available carotenoids, mainly $\beta$-carotene supplements are produced by synthetic means. Globally, there is a rising trend that people are going for natural products including vitamins and carotenes. The synthetic carotenoids especially $\beta$-carotene taken as a supplementation is unlike natural carotenoids which is a mixture of carotenoids compounds, many of which may not be readily metabolized rapidly ${ }^{[4]}$.

Palm oil is the richest plant source of carotenoids in terms of retinol equivalent with $500-700 \mathrm{ppm}$. A total of 11 types of carotenes have been identified in palm $\mathrm{oil}^{[5]}$ as shown in Table 1. However, these carotenoids are destroyed by conventional refining. In light of the importance of natural carotenoids, various methods have been investigated to recover the carotenoids from palm oil before refining. These include saponification $^{[6]}$, adsorption ${ }^{[7]}$, solvent extraction ${ }^{[8]}$ and transesterification of palm oil followed by molecular distillation ${ }^{[9]}$. However, these processes involve the usage of organic solvents, chemical modifications and generate waste that has to be treated before it is allowed to be discharged to watercourse.

Table 1: Various types and composition of carotenes in palm oil

\begin{tabular}{|c|c|}
\hline Types of carotenes & Composition (\%) \\
\hline Phytoene & 1.27 \\
\hline Cis- $\beta$-Carotene & 0.68 \\
\hline Phytofluene & 0.06 \\
\hline$\beta$-Carotene & 56.02 \\
\hline$\alpha$-Carotene & 35.16 \\
\hline Cis- $\alpha$-Carotene & 2.49 \\
\hline$\zeta$-Carotene & 0.69 \\
\hline$\gamma$-Carotene & 0.33 \\
\hline$\delta$-Carotene & 0.83 \\
\hline Neurosporene & 0.29 \\
\hline$\beta$-Zeacarotene & 0.74 \\
\hline$\alpha$-Zeacarotene & 0.23 \\
\hline Lycopene & 1.30 \\
\hline
\end{tabular}

Over the last two decades, supercritical fluid extraction (SFE) has been well received as green and promising technology for extraction of natural products $^{[10]}$. Instead of organic solvents, supercritical carbon dioxide $\left(\mathrm{SC}-\mathrm{CO}_{2}\right)$ is used. Above its critical pressure and temperature, carbon dioxide behaves both like solvent and gas with higher diffusivity and density but lower viscosity ${ }^{[11]}$. The most significant advantages of using $\mathrm{SC}-\mathrm{CO}_{2}$ are (i) its chemical inertness; (ii) its non-toxic, non-hazardous and non-inflammable characteristics; (iii) it leaves no solvent residue in the products and (iv) the process generates no waste, therefore it is environment benign technology.

The solubility of carotenoids has been well established. However, most of the published data 
involved the use of synthetic $\beta$-carotene as the starting material $^{[12-18]}$. It has been reported that discrepancies in solubility data measurements can be due to numerous factors including degradation of carotenoids ${ }^{[19,20]}$, purity of starting material ${ }^{[18]}$ and method of measurement ${ }^{[17]}$.

Since palm oil is a natural source of carotenoids, the determination of solubility of palm carotenoids in $\mathrm{SC}-\mathrm{CO}_{2}$ is important to study the possibility to extract the carotenoids. Markom et al. ${ }^{[21]}$ reported the solubility of palm carotenoids in $\mathrm{SC}-\mathrm{CO}_{2}$ at $20 \mathrm{MPa}$ for temperatures of 40,50 and $60^{\circ} \mathrm{C}$. They found that it was difficult to extract $\beta$-carotene from palm oil even at high pressure of $20 \mathrm{MPa}$ and temperature had little effect on the solubility of $\beta$-carotene in $\mathrm{SC}-\mathrm{CO}_{2}$. Ooi et $a l .{ }^{[22]}$ reported a counter-current column processing of palm oil. The refined oil produced in the raffinate from the process has higher content of carotene. De Franca et $a l .{ }^{[23]}$ reported the SFE of carotenoids from buriti, an Amazon-region palm fruit under limited extraction conditions of $313 \mathrm{~K}$ and $328 \mathrm{~K}$ at pressures of 20 and 30 $\mathrm{MPa}$. They found that a large amount of carotenes were extracted in the diffusion-controlled period due to the reason that carotenes are found in the oleaginous fractions located deep inside the solid particles. Birtigh et $a{ }^{\left[{ }^{[24]}\right.}$ and de Franca and Meireles ${ }^{[25]}$ reported SFE of carotenoids from palm-pressed fibers, a by-product produced during production of crude palm oil (CPO).

\section{MATERIALS AND METHODS}

CPO was obtained from a local palm oil mill. The carbon dioxide with purity of $99.995 \%$ was purchased from Malaysian Oxygen Berhad (Selangor, Malaysia). All other solvents used for analysis were of analyticalgrade purchased from Merck (Darmstadt, Germany).

Apparatus: The SFE system used in this study is shown in Fig. 1. It consists of a $50 \mathrm{ml}$ high pressure extraction vessel placed in a column oven (Model CO960, Jasco, Japan) that can control the temperature to within $\pm 0.1^{\circ} \mathrm{C}$. The pressure of the system was controlled to within $\pm 0.1 \mathrm{MPa}$ by a back pressure regulator (Model 880-81, Jasco, Japan). The carbon dioxide was chilled to $-5^{\circ} \mathrm{C}$ before a HPLC pump (Model PU-986, Jasco, Japan) was used to pump the liquified carbon dioxide into the extractor at a constant flow of $5.0 \mathrm{~mL} \min ^{-1}$, measured at the pump as compressed carbon dioxide.

Methods: CPO (20g) was weighed accurately and loaded into the extraction vessel. The extraction was carried out in a dynamic (flow-through) system. It is assumed that a steady state solute-solvent equilibrium is achieved as the supercritical fluid passes over the solute. Liquid carbon dioxide was pumped continuously into the vessel at the specific extraction conditions. A frit was installed at the outlet of the extraction vessel to

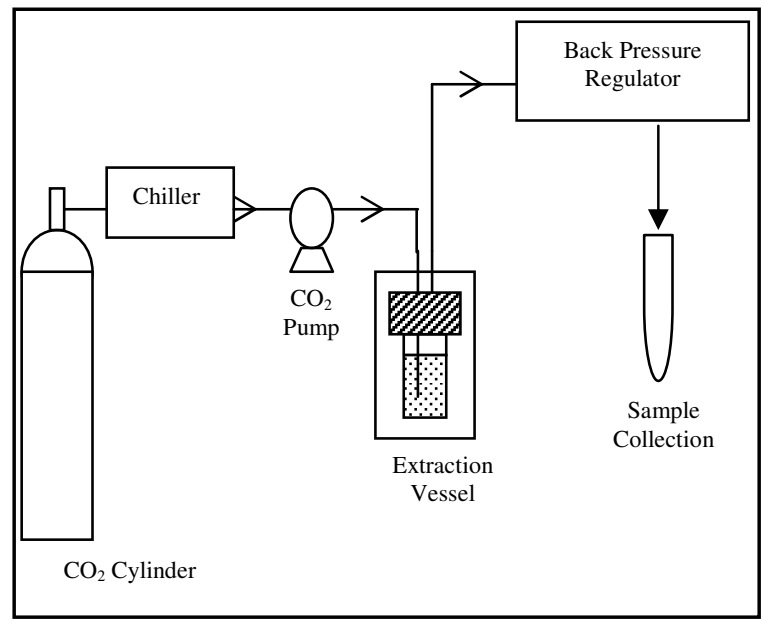

Fig. 1: Flow diagram of supercritical fluid extraction system

prevent any physical carry over of palm oil. The extracts were collected at the outlet of the back pressure regulator at an interval of half hour into container wrapped in aluminium foil. This is to preserve the lightsensitive carotenoids. The extracts were weighed to the nearest $\pm 0.0001 \mathrm{~g}$. The samples were blanketed with nitrogen and kept in the dark at $-10^{\circ} \mathrm{C}$ prior to analysis to prevent any degradation by heat, air and light.

Effect of pressure: The effect of pressure on the extraction of carotenoids from CPO was investigated by conducting the experiments at pressures of 14, 22 and $30 \mathrm{MPa}$. The flow of carbon dioxide was kept constant at $5.0 \mathrm{~mL} \mathrm{~min} \mathrm{~m}^{-1}$ throughout the experiment. The low temperature of $40^{\circ} \mathrm{C}$ was chosen because of the thermally labile characteristics of carotenoids.

Effect of temperature: The effect of temperature on the extraction of carotenoids from CPO was investigated by conducting the experiments at temperatures of 40,60 and $80^{\circ} \mathrm{C}$. Both the extraction pressure and flow of carbon dioxide were kept constant

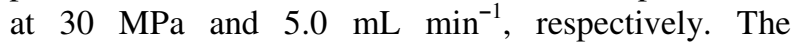
temperatures were used due to the similarity of their densities to that of different pressures at $40^{\circ} \mathrm{C}$ as shown in Table 2.

Effect of flow rate: The effect of flow rate on the extraction of carotenoids from CPO was investigated by conducting the experiments at flow rates of 5.0, 10.0 and $15.0 \mathrm{~mL} \mathrm{~min}{ }^{-1}$. The temperature and pressure were the optimum conditions found in previous experiments.

Effect of sample size: The effect of sample size of the extraction of carotenoids from CPO was investigated by conducting the experiments at sample sizes of $5 \mathrm{~g}, 10 \mathrm{~g}$ and $20 \mathrm{~g}$. The temperature and pressure were the optimum conditions found in previous experiments. 
The flow of carbon dioxide was kept constant at $5.0 \mathrm{~mL} \mathrm{~min}^{-1}$.

Analysis: The total carotenoids content was determined using MPOB Test Methods ${ }^{[26]}$. The off-line approach was used to prevent overloading of carotenoids due to increase concentration and larger sample size in the course of extraction. The sample was homogenized and weighed to the nearest $\pm 0.0001 \mathrm{~g}$ into a $25 \mathrm{ml}$ volumetric flask. The sample was dissolved with $n$ hexane and diluted to the mark. The solution was transferred into a $1 \mathrm{~cm}$ quartz cuvette and the absorbance was measured at $446 \mathrm{~nm}$ against $n$-hexane using UV-visible spectrophotometry (Spectrophotometer Hitachi U-2000). The total carotenoids content was expressed as ppm of $\beta$ carotene. The calculation was as follows:

Carotenoids content $=\left[\mathrm{V} \times 383 \times\left(\mathrm{A}_{\mathrm{s}}-\mathrm{A}_{\mathrm{b}}\right)\right] /(100 \times \mathrm{W})$

Where:

$\mathrm{V}$ is the volume used for analysis

383 is the extinction coefficient for carotenoids

$\mathrm{A}_{\mathrm{S}}$ is the absorbance of the sample

$A_{b}$ is the cuvette error

$\mathrm{W}$ is the weight of the sample in $\mathrm{g}$

\section{RESULTS AND DISCUSSION}

The initial total carotenoids content in CPO was 650 ppm.

Effect of pressure and temperature: The effect of pressure at $40^{\circ} \mathrm{C}$ on the recovery of palm carotenoids (\%) as a function of amount of carbon dioxide $(\mathrm{g})$ is depicted in Fig. 2. It shows that solubility of palm carotenoids increased with pressures at a constant temperature. At a constant temperature, increasing the pressure increases the density of the $\mathrm{SC}-\mathrm{CO}_{2}$. The solvent strength of $\mathrm{SC}-\mathrm{CO}_{2}$ increases with the density and thus increases the solubility of carotenoids. This suggests that the solubility of palm carotenoids in SC$\mathrm{CO}_{2}$ is proportional to the density of $\mathrm{SC}-\mathrm{CO}_{2}$. However, it was not a linear relationship as shown in Table 2 . The solubility of carotenoids increased by $>600 \%$ from 1.31 $\mathrm{x} 10^{-4}$ to $9.41 \times 10^{-4} \mathrm{~g} \mathrm{~kg}^{-1}$ as pressure was increased from 14 to $22 \mathrm{MPa}$. However, the increment was about $60 \%$ from $9.41 \times 10^{-4}$ to $1.53 \times 10^{-3} \mathrm{~g} \mathrm{~kg}^{-1}$ when pressure was increased from 22 to $30 \mathrm{MPa}$. As discussed by $\mathrm{King}^{[27]}$, there is a pressure region where significant increase occurs in the solubility of the solute in supercritical fluid. Thus, from this study it was found that the pressure region for SFE of carotenoids from $\mathrm{CPO}$ was in the range of 14-22 $\mathrm{MPa}$.

At a constant pressure, increasing the temperature reduces the density of $\mathrm{SC}-\mathrm{CO}_{2}$. As carotenoids have no significant vapor pressure, raising the extraction temperature decreases the solubility due to the reduction of solvent density.

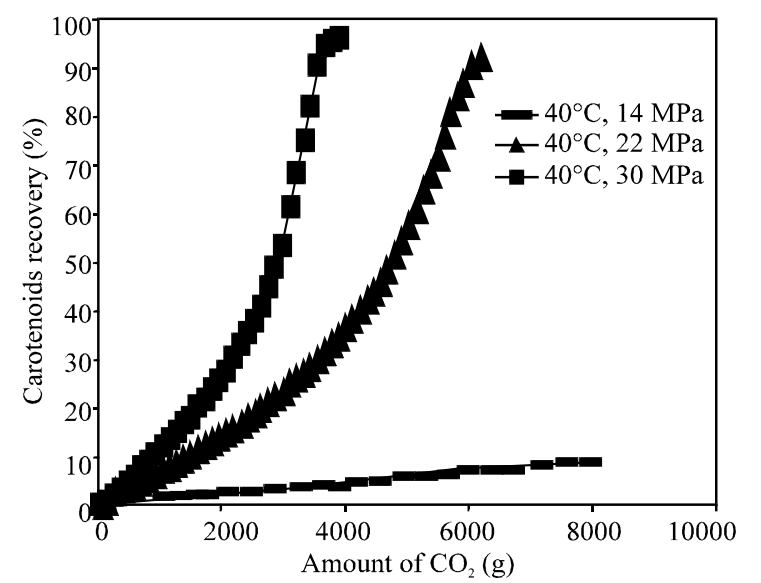

Fig. 2: Effect of pressure at constant temperature of $40^{\circ} \mathrm{C}$ on the solubility of palm carotenoids in $\mathrm{SC}-\mathrm{CO}_{2}$

The solubility of palm carotenoids exhibits retrograde behavior as the solubility was inversely proportionate to the temperatures. However, the influence of temperature on the solubility of carotenoids was insignificant as compared to the influence of pressure. These are shown in the solubility of carotenoids for different temperature at $30 \mathrm{MPa}$ with same order of magnitude (Table 2). The solubility of carotenoids reduced from $1.53 \times 10^{-3}$ to $1.24 \times 10^{-3} \mathrm{~g} \mathrm{~kg}^{-1}$ as the temperature was increased from 40 to $80^{\circ} \mathrm{C}$. It was also observed that the recovery of carotenoids from $\mathrm{CPO}$ was $80 \%$ at high temperature of $80^{\circ} \mathrm{C}$ compared to 40 and $60^{\circ} \mathrm{C}$ with $>90 \%$ recovery. This could be contributed to degradation of selected carotenoids as had been reported by several authors ${ }^{[19,20]}$. Our results were conflicting to that reported by Johannsen and Brunner $^{[14]}$ as well as Sovová et al. ${ }^{[19]}$. Both studies were conducted at temperatures of 40,60 and $80^{\circ} \mathrm{C}$. They reported that increased in temperature resulted in an increased of solubility of $\beta$-carotene. The contradiction can be contributed by the presence of other more soluble components in palm oil which are co-extracted with carotenoids at high temperature resulted in lower carotenoids solubility in the present study. Thus, it is noted that solubility of carotenoids in $\mathrm{SC}-\mathrm{CO}_{2}$ from synthetic form and from natural sources are significantly different.

The results showed that at similar densities of the SC- $\mathrm{CO}_{2}$, the solubility of carotenoids was significantly different (Table 2). For similar densities of $762.0 \mathrm{~kg}$ $\mathrm{m}^{-3}\left(40^{\circ} \mathrm{C}\right.$ and $\left.14 \mathrm{MPa}\right)$ and $739.8 \mathrm{~kg} \mathrm{~m}^{-3}\left(80^{\circ} \mathrm{C}\right.$ and 30 $\mathrm{MPa}$ ), it was found that the solubility of carotenoids differed by one order of magnitude with $1.31 \times 10^{-4}$ and $1.24 \times 10^{-3} \mathrm{~g} \mathrm{~kg}^{-1}$, respectively. This suggests the misconception of using density of the supercritical fluid alone in explaining the solubility of solutes. Thus, the combination of temperature and pressure plays a more important role than density alone in manipulation of solubility of solute in supercritical fluids. However, the use of density to describe the solubility of solute is valid at a constant temperature or a constant pressure. 
Table 2: Solubility of Carotenoids from Crude Palm Oil in $\mathrm{SC}_{-} \mathrm{CO}_{2}$

\begin{tabular}{lccccc}
\hline $\begin{array}{l}\text { Temperature } \\
\left({ }^{\circ} \mathrm{C}\right)\end{array}$ & $\begin{array}{l}\text { Pressure } \\
(\mathrm{MPa})\end{array}$ & $\begin{array}{l}\text { Density of SC-CO } \\
\left(\mathrm{kg} \mathrm{m}^{-3}\right)\end{array}$ & $\begin{array}{l}\text { Feed Size } \\
(\mathrm{g})\end{array}$ & $\begin{array}{l}\text { Flow rate of SC-CO } \\
\left(\mathrm{mL} \mathrm{min}^{-1}\right)\end{array}$ & $\begin{array}{c}\text { Solubility of Carotenoids } \\
\mathrm{x} \mathrm{10} 0^{-3}\left(\mathrm{~g} \mathrm{~kg}^{-1}\right)\end{array}$ \\
\hline 40 & 14 & 762.0 & 20 & 5 & 0.131 \\
40 & 22 & 861.2 & 20 & 5 & 0.941 \\
40 & 30 & 912.4 & 20 & 5 & 1.53 \\
60 & 30 & 833.5 & 20 & 5 & 1.33 \\
80 & 30 & 739.8 & 20 & 5 & 1.24 \\
40 & 30 & 912.4 & 10 & 5 & 1.57 \\
40 & 30 & 912.4 & 5 & 5 & 1.58 \\
40 & 30 & 912.4 & 20 & 10 & 1.54 \\
40 & 30 & 912.4 & 20 & 15 & 1.56 \\
\hline
\end{tabular}

Table 3: Model parameters for carotenoids estimated using Chrastil model at $40^{\circ} \mathrm{C}$

\begin{tabular}{|c|c|c|c|c|}
\hline References & $\mathrm{k}$ & $\mathrm{a}$ & $\mathrm{b}$ & $\Delta \mathrm{H}\left(\mathrm{J} \mathrm{mol}^{-1}\right)$ \\
\hline This study & 8.08 & 4217 & -19.22 & $3.5 \times 10^{4}$ \\
\hline Sakaki $^{[12]}$ & 9.3 & NA & $-34.28 *$ & $7.2 \times 10^{4}$ \\
\hline Škerget et al. ${ }^{[13]}$ & 5.47 & 6287.9 & -15.43 & $5.2 \times 10^{4}$ \\
\hline Güçlü-Üstündağ and Temelli ${ }^{[30]}$ & 7.2 & -8844.3 & -26.8 & NA \\
\hline Subra et al..$^{[17]}\left(37^{\circ} \mathrm{C}\right)$ & 9.9 & NA & NA & NA \\
\hline
\end{tabular}

$* \mathrm{~b}=\mathrm{q}-\ln \left(\left[1000 \mathrm{M}_{\mathrm{B}}\right]^{\left.\mathrm{k} /\left[\mathrm{M}_{\mathrm{A}}+\mathrm{kM}_{\mathrm{B}}\right]\right)}\right.$

$\mathrm{NA}=$ not available

Effect of sample size and flow rate: The effect of sample size on the recovery of palm carotenoids $(\%)$ as a function of time (hour) is shown in Fig. 3. From Fig. 3 , reduction of sample size from $20 \mathrm{~g}$ to $10 \mathrm{~g}$ reduced the extraction time to half from 17 hours to 9 hours. It was found that the sample size of CPO loaded into the extraction vessel was linearly proportional to the rate of carotenoids extraction. The solubility of carotenoids for the three sample sizes were in the range of $1.53 \times 10^{-3}$ to $1.58 \times 10^{-3} \mathrm{~g} \mathrm{~kg}^{-1}$ carbon dioxide (Table 2). It was observed that the solubility of carotenoids in $\mathrm{SC}-\mathrm{CO}_{2}$ was independent of the sample size of the CPO loaded into the extraction vessel. The results showed that the removal of carotenoids from the extraction vessel by supercritical fluid is the rate-determining step that depends on the volume of the fluid.

The results are further supported by the effect of flow rate on the recovery of carotenoids (\%). The higher flow rate applied resulted in faster extraction rates thus shorter extraction time. Linear correlation was observed for the flow rates and the extraction rates. Double the flow rate from 5 to $10 \mathrm{~mL} \mathrm{~min}^{-1}$ reduced the extraction time to half. This confirmed that rapid diffusion of carotenoids from the oil matrix and the extraction is controlled by the ability of $\mathrm{SC}-\mathrm{CO}_{2}$ for solvation. Again the solubility of palm carotenoids were not significantly affected by the flow rate employed with solubility in the range of $1.54 \times 10^{-3}$ to $1.58 \times 10^{-3}$ $\mathrm{g} \mathrm{kg}^{-1}$ carbon dioxide (Table 2).

The results disagree with those of de Franca et $a l .{ }^{[23]}$ that reported that large amount of carotenes were extracted in the diffusion-controlled period. As the flow rates investigated were in the range of $0.29-0.43 \mathrm{~g}$ $\mathrm{s}^{-1}$ were relatively narrow and thus the effect was insignificant. This can be attributed by the different matrix used in both studies.
Comparison with literature: The solubility of carotenoids found in the present study is in the range of $1.31 \times 10^{-4}$ to $1.58 \times 10^{-3} \mathrm{~g} \mathrm{~kg}^{-1}$ for pressures investigated (Table 2). The solubility is one order of magnitude lower than those reported by Johannsen and Brunner ${ }^{[14]}$ with $1 \times 10^{-3}$ to $4 \times 10^{-2} \mathrm{~g} \mathrm{~kg}^{-1}$ ). High purity trans- $\beta$-carotene of $95 \%$ was used in their study while our study determined the solubility of carotenoids from CPO. Thus, the competing effect of other more soluble components present in $\mathrm{CPO}$ may contribute to lower solubility of carotenoids in $\mathrm{SC}-\mathrm{CO}_{2}$.

The mole fractions of carotenoids soluble in SC$\mathrm{CO}_{2}$ at $40^{\circ} \mathrm{C}$ (unless otherwise stated) from various studies are shown in Fig. 4. It was found that solubility data reported by Cygnarowicz et al. ${ }^{[15]}$ was the lowest published data and disagreed with other workers. They used a recirculating loop with an in-line UV detector to investigate the solubility of pure crystalline $\beta$-carotene. These are the possible reasons for the substantial difference from our data. The solubility data reported by Hansen et al. ${ }^{[28]}$ was similar to our results at low pressure but at high pressures, their values are lower than ours. Hansen and co-workers determined the solubility of carotenes from carrots with purity $>95 \%$ which consists of a mixture of isomers of $\alpha-$ and $\beta$-carotenes at a ratio of 1 to 2 . As the pressure increases, other carotenoids besides the $\alpha-$ and $\beta$-carotenes present in palm oil may be more soluble thus increases the solubility.

Sakaki $^{[12]}$, Subra et $a l .{ }^{[17]}$ and Mendes et $a l .{ }^{[18]}$ have similar solubility data although Subra et al. worked at $37^{\circ} \mathrm{C}$. Their results were relatively higher than our present study. The major discrepancy can be contributed to the purity of $\beta$-carotene used and the presence of other more soluble solutes. The solubility determined in our study was the carotenoids present in CPO with 650 ppm $(0.065 \%)$ while most authors used 


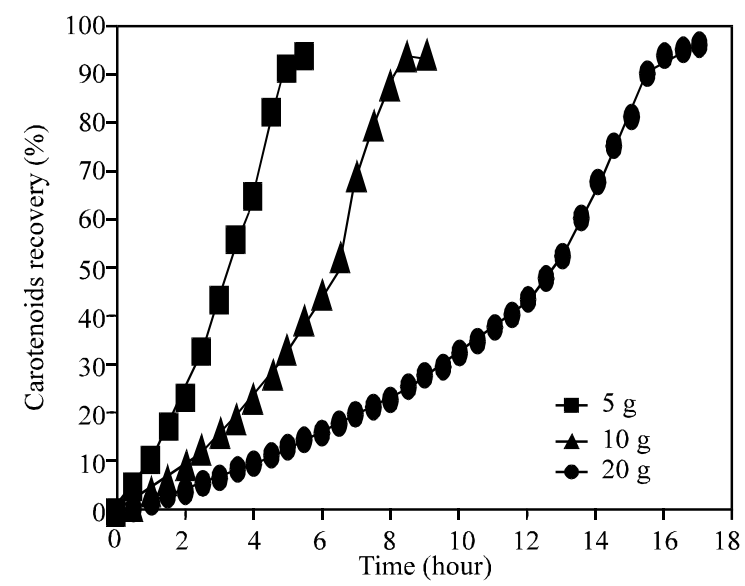

Fig. 3: Effect of sample size on the solubility of palm carotenoids in $\mathrm{SC}-\mathrm{CO}_{2}$
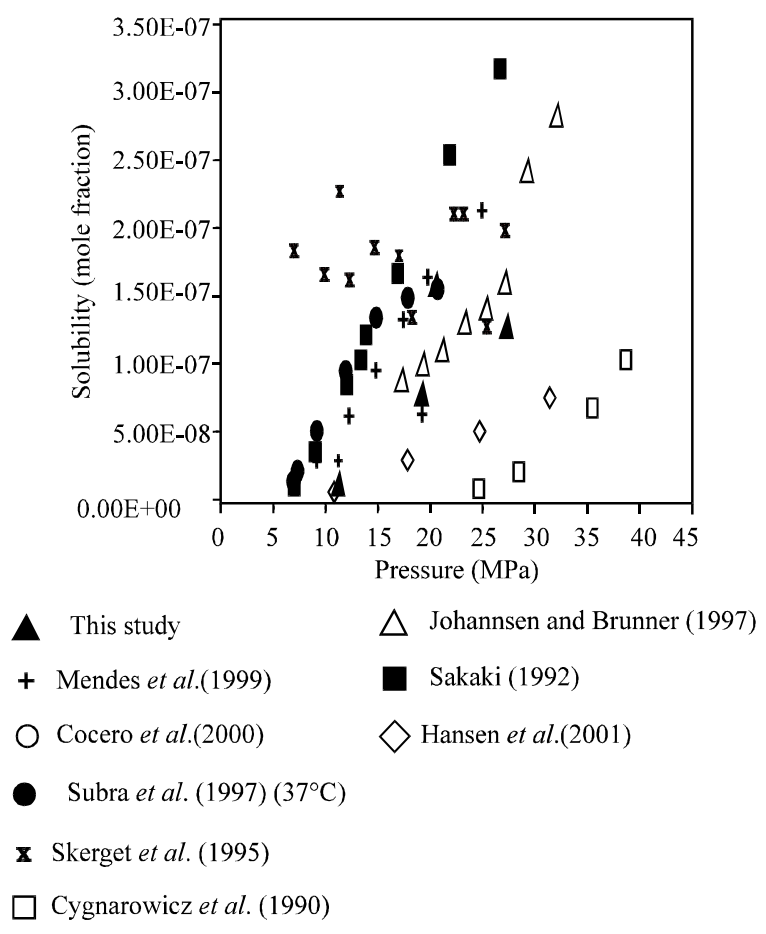

Fig. 4: Solubility of carotenoids in $\mathrm{SC}-\mathrm{CO}_{2}$ at $40^{\circ} \mathrm{C}$

synthetic $\beta$-carotene with purity of $>97 \%$. The results of our study showed that the threshold pressure of SFE of carotenoids from $\mathrm{CPO}$ at $40^{\circ} \mathrm{C}$ was $13 \mathrm{MPa}$.

Solubility data and modeling: The solubility data obtained in the present study was correlated using a density-based equation as proposed by Chrastil ${ }^{[29]}$. This model was based on the direct relationship between solubility and density (concentration) of a solvent. The calculation of the equilibrium concentration was based on the formation of a solvato complex upon the association of a solute with the molecules of the solvent. The equation derived was as follows:

$\ln c=k \ln d+a / \mathrm{T}+b$
Where:

C

$d$

$k$

$a$

$\Delta \mathrm{H} \quad$ is total reaction entalphy

$\mathrm{R} \quad$ is the gas constant

$b \quad$ is $\ln \left(\mathrm{M}_{\mathrm{A}}+\mathrm{kM}_{\mathrm{B}}\right)+\mathrm{q}-\mathrm{k} \ln \mathrm{M}_{\mathrm{B}}$

$\mathrm{M}_{\mathrm{A}}$ and $\mathrm{M}_{\mathrm{B}}$ are the molecular weights of the solute and the solvent, respectively

$q$

Model parameters estimated using the above equation and comparison with other authors using similar models are presented in Table 3. The association number, $k$ from our present study at $40^{\circ} \mathrm{C}$ is 8.08. This shows that 8.08 molecules of carotenoids were associated with one molecule of $\mathrm{CO}_{2}$. The values of our present study fall in the range of reported data.

The total reaction entalphy, $\Delta \mathrm{H}$, found in the present study was in the same order of magnitude with that reported by Sakaki ${ }^{[12]}$ and Škerget et al. ${ }^{[13]}$. Only a slight deviation in the total reaction entalphy was observed.

Although some inconsistencies were observed, the variation between literatures can be attributed to (i) purity of samples, (ii) origin of samples, (iii) method for measurement of solubility (i.e. dynamic or static, online or offline), (iv) degradation of carotenoids and (v) isomerisation of carotenoids.

The study shows that carotenoids from CPO has very low solubility in $\mathrm{SC}-\mathrm{CO}_{2}$ at temperatures in the range of $40-80^{\circ} \mathrm{C}$ and pressures in the range of $14-30$ MPa. Its solubility was in the range of $1.31 \times 10^{-4}$ to $1.58 \times 10^{-3} \mathrm{~g} \mathrm{~kg}^{-1}$ carbon dioxide. The knowledge of the low solubility of carotenoids provides useful information to possibly exploit SFE for fractionation of valuable components present in CPO.

\section{ACKNOWLEDGMENTS}

The authors wish to thank Director General of MPOB for permission to publish this paper. Puah Chiew Wei thanks MPOB for Research Graduate Assistantship to do her Ph.D.

\section{REFERENCES}

1. Burton, G.W. and K.U. Ingold, 1984. Betacarotene: An unusual type of lipid antioxidant. Science, 224: 569-573.

2. Di Mascio, P., M.E. Murphy and H. Sies, 1991. Antioxidant defense systems: The role of carotenoids, tocopherols and thiols. Am. J. Clin. Nutr., 53: 194S-200S. 
3. Slattery, M.L., J. Benson, K. Curtin, K.N. Ma, D. Schaeffer and J.D. Potter, 2000. Carotenoids and colon cancer. Am. J. Clin. Nutr., 71: 575-582.

4. Goh, S.H., 1996. Carotene controversy. Malaysian Oil Sci. and Technol., 5: 17.

5. Yap, S.C., 1995. Palm oil carotenes: Chemistry and technology. Ph.D Thesis, University of Malaya, Kuala Lumpur, pp: 94.

6. Blaizot, P.P., 1953. Method of obtaining carotene from palm oil. US Patent 2652433.

7. Oishida, A., I. Hama, A. Okabe and Y. Tanaka, 1986. A process for producing carotene from oils and fats. British Patent 2160874.

8. Drescher, M., P. Siegfried and E. Weidner, 2002. Process for extracting carotenes from carotenecontaining materials. US Patent 6407306.

9. Ooi, C.K., Y.M. Choo, S.C. Yap, Y. Basiron and A.S.H. Ong, 1994. Recovery of carotenoids from palm oil. J. Am. Oil Chem. Soc., 71: 423.

10. McHugh, M.A. and V.J. Krukonis, 1994. Supercritical Fluid Extraction: Principles and Practice. 2nd Edn., pp: 1, Butterworth-Heinemann Series in Chemical Engineering, USA

11. Blomberg, L.G., M. Demirbüker and $M$. Andersson, 1998. Characterization of lipids by supercritical fluid chromatography and supercritical fluid extraction. In: Lipid Analysis in Oils and Fats, (Ed. R.J. Hamilton) pp: 34, Blackie Academic \& Professional, Great Britain.

12. Sakaki, K., 1992. Solubility of $\tilde{\beta}$ carotene in dense carbon dioxide and nitrous oxide from 308 to 323 $\mathrm{K}$ and from 9.6 to $30 \mathrm{MPa}$. J. Chem. Eng. Data, 37: 249-251.

13. Škerget, M., Ž. Knez and M. Habulin, 1995. Solubility of $\tilde{\beta}$ carotene and oleic acid in dense $\mathrm{CO}_{2}$ and data correlation by a density based model. Fluid Phase Equilibria, 109: 131-138.

14. Johannsen, M. and G. Brunner, 1997. Solubilities of the fat-soluble vitamins $\mathrm{A}, \mathrm{D}, \mathrm{E}$ and $\mathrm{K}$ in supercritical carbon dioxide. J. Chem. Eng. Data, 42: 106-111.

15. Cygnarowicz, M.L., R.J. Maxwell and W.D. Seider, 1990. Equilibrium solubilities of $\beta$-carotene in supercritical carbon dioxide. Fluid Phase Equilibria, 59: 57-71.

16. Jay, A.J. and D.C. Steytler, 1992. Nearcritical fluids as solvents for $\beta$-carotene. J. Supercrit. Fluids, 5: 274-282.

17. Subra, P., S. Castellani, H. Ksibi and Y. Garrabos, 1997. Contribution to the determination of the solubility of $\beta$-carotene in supercritical carbon dioxide and nitrous oxide: Experimental data and modeling, Fluid Phase Equilibria, 131: 269-286.
18. Mendes, R.L., B.P Nobre, J.P. Coelho and A.F. Palavra, 1999. Solubility of $\tilde{\beta}$ carotene in supercritical carbon dioxide and ethane. J. Supercrit. Fluids, 16: 99-106.

19. Sovová, H., R.P. Stateva and A.A. Galushko, 2001. Solubility of $\tilde{\beta}$ carotene in supercritical $\mathrm{CO}_{2}$ and the effect of entrainers. J. Supercrit. Fluids, 21: 195203.

20. Cocero, M.J., S. González, S. Pérez and E. Alonso, 2000. Supercritical extraction of unsaturated products. Degradation of $\beta$-carotene in supercritical extraction processes. J. Supercrit. Fluids, 19: 39-44.

21. Markom, M., H. Singh and M. Hasan, 2001. Supercritical $\mathrm{CO}_{2}$ fractionation of crude palm oil. J. Supercrit. Fluids, 20: 45-53.

22. Ooi, C.K., A. Bhaskar, M.S. Yener, D.Q. Tuan, J. Hsu and S.S.H. Rizvi, 1996. Continuous supercritical carbon dioxide processing of palm oil. J. Am. Oil Chem. Soc., 73: 233-237.

23. de Franca, L.F., G. Reber, M.A.A. Meireles, N.T. Machado and G. Brunner, 1999. Supercritical extraction of carotenoids and lipids from buriti (Mauritia flexuosa), a fruit from the Amazon region. J. Supercrit. Fluids, 14: 247-256.

24. Birtigh, A., M. Johannsen, G. Brunner and N. Nair, 1995. Supercritical-fluid extraction of oil-palm components. J. Supercrit. Fluids, 8: 46-50.

25. de Franca, L.F. and M.A.A. Meireles, 2000. Modeling the extraction of carotene and lipids from pressed palm oil (Elaeis guineensis) fibers using supercritical $\mathrm{CO}_{2}$. J. Supercrit. Fluids, 18: 35-47.

26. MPOB Test Methods, 2005. Determination of carotene content, Malaysian Palm Oil Board, Method No. p 2.6, pp: 194-197.

27. King, J.W., 1990. Analytical supercritical fluid extraction. In: Analytical Supercritical Fluid Chromatography and Extraction. (Eds. M.L. Lee and K.E. Markides), pp: 317, Chromatography Conferences, Inc.

28. Hansen, B.N., A.H. Harvey, J.A.P. Coelho, A.M.F. Palavra and T.J. Bruno, 2001. Solubility of capsaicin and $\beta$-carotene in supercritical carbon dioxide and in halocarbons. J. Chem. Eng. Data, 46: 1054-1058.

29. Chrastil, J., 1982. Solubility of solids and liquids in supercritical gases. J. Phys. Chem., 86: 3016-3021.

30. Güçlü-Üstündağ, Ö, and F. Temelli, 2004. Correlating the solubility behavior of minor lipid components in supercritical carbon dioxide. J. Supercrit. Fluids, 31: 235-253. 